\title{
FORMAÇÃO DOCENTE E O ENSINO DA LINGUA PORTUGUESA: ARTICULAÇÃO ENTRE A TEORIA QUE FUNDAMENTA A PRÁTICA
}

\author{
TEACHER TRAINING AND THE TEACHING OF PORTUGUESE LANGUAGE: \\ RELATIONSHIP BETWEEN THE THEORY THAT THE PRACTICE BASICS
}

Sueli Gedoz ${ }^{54}$ \& Terezinha da Conceição Costa-Hübes ${ }^{55}$

\section{Resumo}

O objetivo do presente trabalho é a apresentação do projeto de pesquisa e extensão "Formação continuada para professores da educação básica nos anos iniciais: ações voltadas para a alfabetização em municípios com baixo IDEB na região oeste do Paraná", desenvolvido na região oeste do Paraná, financiado pela CAPES/INEP, conforme Edital 038/2010 do Programa Observatório da Educação. Tal projeto está se consolidando a partir da oferta de formação continuada a docentes, processo que proporciona aprofundamento teórico, encaminhamentos práticos e reflexões sobre o trabalho com a Língua Portuguesa focalizando os gêneros discursivos. Para este estudo, apresentamos, inicialmente, o projeto em questão, seguido de informações sobre os trabalhos de formação realizados com a intenção de minimizar o descompasso presente entre a teoria que perpassa a formação do professor e a sua prática em sala de aula. Tomamos como bases teóricas os estudos de AMOP (2007), Bakhtin (2000, 2004), Bronckart (2003) e Costa-Hübes (2008).

PALAVRAS-CHAVE: Língua Portuguesa, Formação Continuada, Observatório Educacional.

\section{Abstract}

The aim of this paper is to present the project "Continuing education for teachers of basic education in the early years: actions for literacy in cities with low IDEB in western Paraná", supported by CAPES/INEP, as notice 038/2010 - Programa Observatório Educacional, and developed in western Paraná. This project is consolidating from the provision of continuing education for teachers, a process that provides deeper theoretical, referrals and practical reflections on working with the Portuguese language focusing on the speech genres. For this study, we present initially the project in question, followed by information on the work carried out training with the intention of minimizing the gap between the present theory that pervades teacher education and practice in the classroom. We take as theoretical studies AMOP (2007), Bakhtin (2000, 2004), Bronckart (2003) and Costa Hübes (2008).

KEYWORDS: Portuguese Language, Continuing Education, Observatório Educacional.

\section{Introdução}

Elaboramos o presente texto com o intuito de apresentarmos algumas ações que tem produzido resultados satisfatórios no que tange à relação entre teoria e prática presente no processo de formação continuada de docentes. Nosso objetivo pauta-se

\footnotetext{
${ }^{54}$ Doutoranda do Programa de Pós-Graduação Stricto Sensu em Letras, área de concentração em Linguagem e Sociedade, Universidade Estadual do Oeste do Paraná - UNIOESTE; Profa da Educação Básica SEED/PR. oi sueli@hotmail.com

${ }^{55}$ Prof $^{\mathrm{a}} \mathrm{Dr}^{\mathrm{a}}$ do Programa de Pós-Graduação Stricto Sensu em Letras, área de concentração em Linguagem e Sociedade, Nível de Mestrado e Doutorado, Universidade Estadual do Oeste do Paraná - UNIOESTE. terecostahubes@yahoo.com.br
}

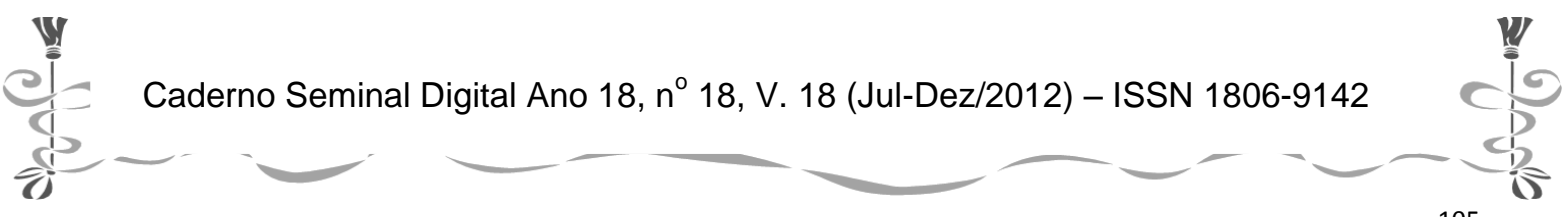




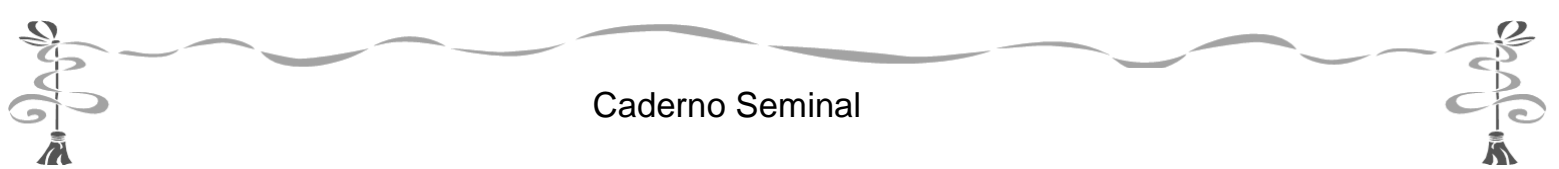

na apresentação de um projeto de pesquisa e extensão que vislumbra esse processo de formação como um dos fatores responsáveis pela elaboração de um trabalho mais significativo para o ensino da Língua Portuguesa.

Ao longo do texto, apresentaremos o projeto denominado "Formação continuada para professores da educação básica nos anos iniciais: ações voltadas para a alfabetização em municípios com baixo IDEB na região oeste do Paraná". Trata-se de um trabalho vinculado ao Programa de Pós-Graduação Stricto Sensu em Letras, nível de Mestrado e Doutorado, com área de concentração em Linguagem e Sociedade, da Universidade Estadual do Oeste do Paraná - UNIOESTE, campus de Cascavel/PR, e financiado pelo Programa Observatório da Educação (CAPES/INEP). As ações organizadas almejam uma contribuição para o processo de formação continuada de docentes dos anos iniciais do Ensino Fundamental, na região oeste do Paraná, por meio de um trabalho sistemático, articulado e contínuo, estendido a esses profissionais.

Por meio desse projeto temos promovido discussões, que estão contribuindo para a melhoria da prática de ensino de Língua Portuguesa de diversos docentes, as quais pretendemos demonstrar neste trabalho. Assim sendo, dedicamos a parte inicial do estudo à apresentação mais abrangente do Programa Observatório da Educação, contextualizando o espaço em que se desenvolve o projeto a ele vinculado, e relatando sobre a elaboração, aprovação e objetivos desse projeto. Em seguida, fundamentamos o olhar que estabelecemos para o trabalho com a Língua Portuguesa na sala de aula, apontando aspectos relacionados aos fundamentos teóricos que embasam a prática docente nos municípios de abrangência do projeto. Com essa fundamentação, apresentamos, na parte final deste texto, o resultado de um trabalho de formação contínuo e sistematizado, oferecido a docentes dos anos iniciais do Ensino Fundamental, indicando ações que mostram a articulação entre a teoria e a prática de ensino na disciplina de Língua Portuguesa.

\section{O Programa Observatório da Educação: elaboração e aprovação de um projeto de formação continuada}

O projeto mencionado "Formação continuada para professores da educação básica nos anos iniciais: ações voltadas para a alfabetização em municípios com baixo IDEB na região oeste do Paraná" foi aprovado em outubro de 2010 pela Coordenação de Aperfeiçoamento de Pessoal de Nível Superior - CAPES - e pelo Instituto Nacional de Estudos e Pesquisas Educacionais Anísio Teixeira - INEP. Sua elaboração deu-se a partir da necessidade de ofertar formação continuada para professores que atuam nos anos iniciais do Ensino Fundamental, em municípios do oeste paranaense que, em 2009, apresentaram Índice de Desenvolvimento da Educação Básica - IDEB - abaixo de 5,0 (cinco).

Em junho de 2010, a CAPES e o INEP lançaram o Edital 038/2010 - Observatório da Educação, por meio do qual convidavam Instituições de Educação Superior que,

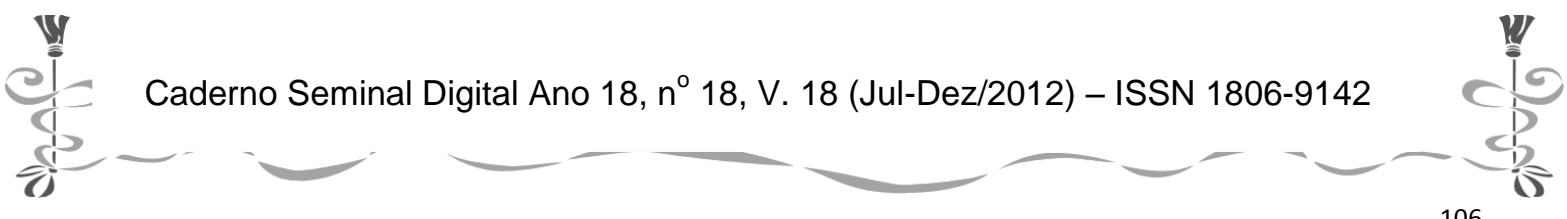




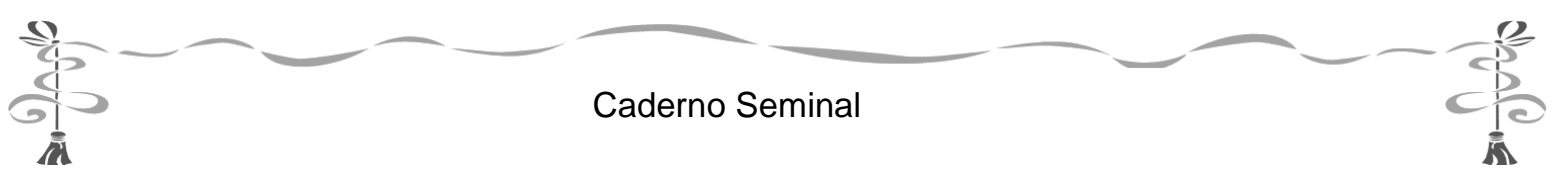

naquele momento, mantinham programas de pós-graduação stricto sensu com conceito maior ou igual a 3 (três), a enviarem propostas de estudos e pesquisas de acordo com a necessidades apresentadas no referido edital. Ao lançar essa proposição, o Programa Observatório da Educação objetivou o fomento de estudos e pesquisas sobre os processos de Alfabetização, de domínio da Língua Portuguesa e da Matemática, bem como a produção acadêmica e a formação de recursos humanos em educação, em nível de pós-graduação, mestrado e doutorado, para, com isso, entre outras metas, fortalecer o diálogo entre a comunidade acadêmica, os gestores das políticas nacionais de educação e os diversos atores envolvidos no processo educacional.

O Programa de Pós-Graduação Stricto Sensu em Letras, nível de Mestrado e Doutorado, com área de concentração em Linguagem e Sociedade ${ }^{56}$, da UNIOESTE, campus de Cascavel/PR, interessou-se pelo Programa Observatório da Educação e elaborou um projeto que, ao mesmo tempo, atendesse aos objetivos do Observatório da Educação e às necessidades de formação continuada nas áreas de Alfabetização, Língua Portuguesa e Matemática em alguns municípios da região oeste de Paraná. A proposição de um projeto ao Edital 38/2010 CAPES/INEP só ocorreu porque a equipe ${ }^{57}$ que constitui e organizou esse projeto acreditou na possibilidade de articular os objetivos do Programa Observatório da Educação aos estudos realizados na linha de pesquisa "Linguagem: práticas linguísticas, culturais e de ensino" do referido Programa de Pós-Graduação. Tais estudos versam, entre outras concepções, sobre a teoria dos gêneros discursivos/textuais, a concepção sociointeracionista de linguagem, o referencial apresentado no Currículo Básico para a Escola Pública Municipal (doravante CBEPM) (AMOP, 2007) e o processo de formação continuada desenvolvido na região oeste do Paraná.

Foi elaborado, então, o projeto, o qual obteve aprovação junto à CAPES/INEP em 08 de outubro de 2010. Traçou-se, então, como objetivo geral, a necessidade de implementar um núcleo de pesquisas focalizando os estudos que valorizassem a alfabetização como um processo essencial ao exercício de práticas sociais de leitura, numeramento, oralidade e escrita, de forma que, por meio de ações voltadas às políticas educacionais de cada município e, dentre elas, a formação continuada de docentes, promovesse o sucesso escolar de municípios da região oeste do Paraná que apresentaram, no ano de 2009, IDEB abaixo de 5,0. Em termos gerais, as metas desse projeto era levantar, por meio de pesquisas, as dificuldades dos alunos dos anos iniciais em leitura e escrita (na área de Língua Portuguesa) e resolução de problemas (em Matemática) para, a partir de tais dados, articular aprofundamentos

\footnotetext{
${ }^{56}$ Em 2010 o referido Programa de Pós-Graduação contava apenas com o curso de Mestrado. Atualmente oferta Mestrado e Doutorado com área de concentração em Linguagem e Sociedade.

${ }^{57}$ Equipe coordenada pela Profa Dra Terezinha da Conceição Costa-Hübes, docente do Programa de Pós-Graduação Stricto Sensu em Letras, Mestrado e Doutorado em Linguagem e Sociedade, UNIOESTE.
}

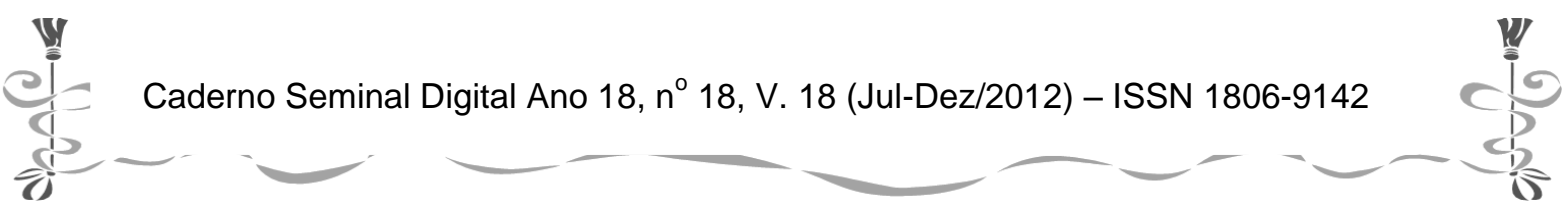




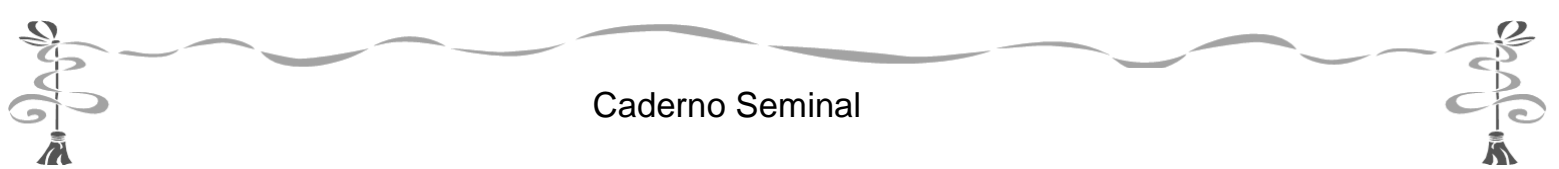

teóricos com os professores em momentos de formação continuada, visando proporcionar-lhes reflexões em relação ao (não) domínio dos conteúdos das disciplinas. No que se refere à Língua Portuguesa, as reflexões voltaram-se para a alfabetização e o letramento a partir de um trabalho pautado nos gêneros discursivos/textuais, base teórica e metodológica do CBPEM (AMOP, 2007).

Para dar conta do objetivo proposto, configuramos, em 2011, um Núcleo de Pesquisa formado por 25 pesquisadores, sendo eles: 03 bolsistas CAPES da Pósgraduação e 01 bolsista Fundação Araucária também da pós-graduação; 06 bolsista CAPES da graduação em Letras; 06 bolsistas CAPES - Professores da Educação Básica; 04 bolsistas PIBIC (CNPq, Fundação Araucária e UNIOESTE); e 5 pesquisadores voluntários (professores da Educação Básica).

Uma vez constituído o Núcleo de Pesquisa, lançamos um olhar para o oeste paranaense, considerando os dados obtidos por Costa-Hübes (2008) em pesquisa realizada sobre o perfil dos docentes nos diversos municípios dessa região. A pesquisa revelou que a maioria dos municípios, apesar de administrar uma quantidade pequena de docentes, não consegue organizar e ofertar uma formação continuada com carga horária significativa na área de Língua Portuguesa. Tal situação é assim justificada pela autora:

O resultado pode ser justificado, de certa forma, pelo fato de não ser apenas a área de Língua Portuguesa que requer formação. [...] os recursos destinados à formação continuada são distribuídos geralmente entre cursos de 8 horas em cada área, ou, então, prioriza-se uma disciplina em detrimento das demais.

Tal realidade justifica o pouco investimento em formação continuada na área de Língua Portuguesa, e revela também qual é a cultura que persiste em relação à formação: cursos pontuais (8 horas), direcionados, cada vez, a uma diferente área, o que parece não garantir as reflexões necessárias para cada uma delas. (COSTA-HÜBES, 2008, p. 187)

Em observância a essa realidade, acreditamos que o interesse pela formação de professores da educação básica, especialmente àqueles que atuam nos anos iniciais do Ensino Fundamental, deve ser o elemento norteador do projeto em questão, pois partimos da hipótese de que, muitas vezes, as dificuldades dos alunos passam, também, pelo conhecimento do professor em relação ao conteúdo avaliado. Sendo assim, a ênfase aos processos de leitura, escrita e numeramento nos anos iniciais do Ensino Fundamental foi no sentido de ampliar/aprofundar o conhecimento científico do docente e, consequentemente, propiciar aos alunos maior domínio e desenvolvimento nos níveis subsequentes do ensino.

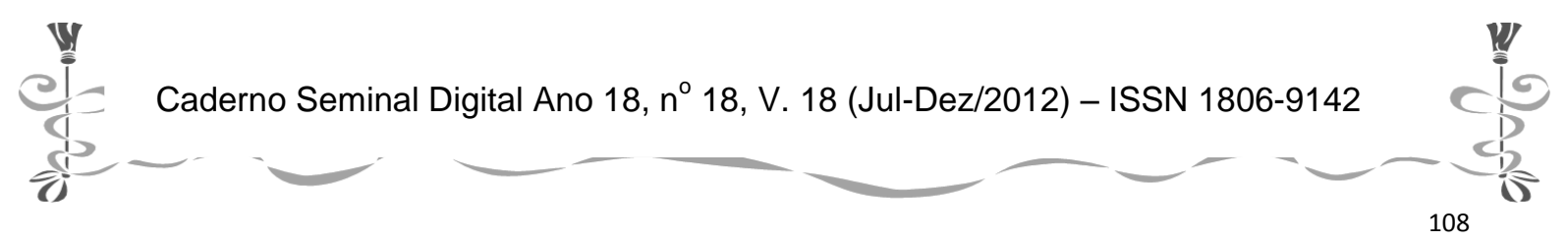




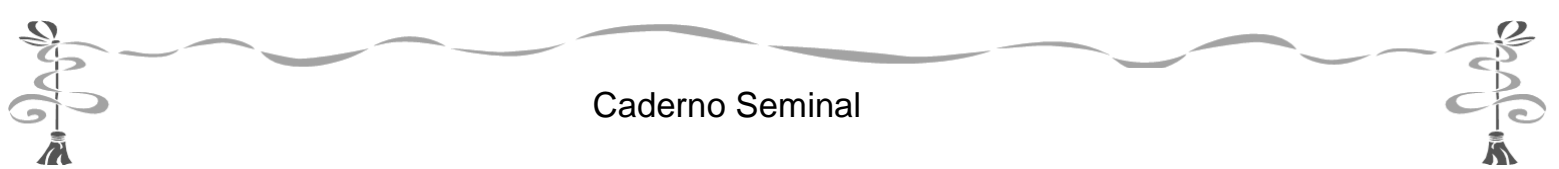

Em termos de avaliação da realidade brasileira, tomamos os dados apresentados nos resultados do $\mathrm{IDEB}^{58}$. Ao analisarmos esse dados, nossa preocupação recaiu sobre 8 municípios do oeste do Paraná, que apresentaram índice inferior a 5,0 (cinco). Embora tais municípios façam parte de um contexto regional que tem um histórico representativo de formação continuada para docentes, os resultados revelaram a necessidade de uma atenção especial ao processo educativo desenvolvido em cada realidade municipal.

Dessa forma, considerando que o projeto organiza-se em torno desses municípios, não podemos deixar de considerar, em nossas ações, estudos relacionados à organização da Prova Brasil. Sabemos que o IDEB de cada município é calculado com base nas taxas de aprovação e no desempenho dos alunos em avaliações desenvolvidas e aplicadas pelo INEP, visando avaliar a qualidade do ensino oferecido pelo sistema educacional brasileiro a partir de testes padronizados e questionários socioeconômicos. Verificando que a avaliação aplicada aos estudantes do $5^{\circ}$ ano $/ 4^{a}$ série é a Prova Brasil, cujo enfoque, na área de Língua Portuguesa, é a leitura, nosso olhar voltou-se para a matriz de referência dessa avaliação e, consequentemente, para os tópicos e descritores que organizam a prova.

Assim, partindo desse contexto, iniciamos, em janeiro de 2011, as ações programadas no projeto. Dentre as várias ações previstas, diversas estão intimamente relacionadas ao ensino da Língua Portuguesa. Sobre essas ações, desenvolvidas ao longo desse período de formação continuada, dedicamos as partes seguintes deste estudo. $\mathrm{Na}$ sequência, apresentamos a fundamentação teórica que embasa as discussões relacionadas ao ensino da Língua Portuguesa e, posteriormente, algumas ações empreendidas nos momentos de formação continuada.

\section{A teoria que fundamenta a prática para o ensino da Língua Portuguesa}

Com atividades iniciadas em janeiro de 2011, os pesquisadores envolvidos no projeto $^{59}$, mais especificamente os da área de Língua Portuguesa, têm realizado pesquisas e ações práticas sobre os processos de alfabetização, letramento e domínio da Língua Portuguesa, com base teórica voltada à interação verbal proposta por Bakhtin $(2000,2004)$ e ao interacionismo sócio-discursivo apresentado por Bronckart (2003). Compreendendo a linguagem sob esse foco, a alfabetização e o letramento também são tomados a partir dos usos da escrita e da leitura nas práticas sociais. Trata-se, portanto, de um trabalho que se fundamenta no enfoque que

\footnotetext{
${ }^{58}$ O Índice de Desenvolvimento da Educação Básica (IDEB) foi criado em 2007 com o objetivo de verificar a qualidade de cada escola e de cada rede de ensino. O indicador é calculado com base no desempenho do estudante em avaliações do INEP e em taxas de aprovação.

${ }^{59}$ Em 2012, a pedido dos municípios, iniciaram-se as atividades na área de Matemática. Para isso, a composição atual dos bolsistas da graduação e da Educação Básica é a seguinte: 03 alunos do Curso de Letras e 03 do Curso de Pedagogia; 03 professores da Educação Básica voltados para a Matemática e os outros 03 dando continuidade às ações em Língua Portuguesa.
}

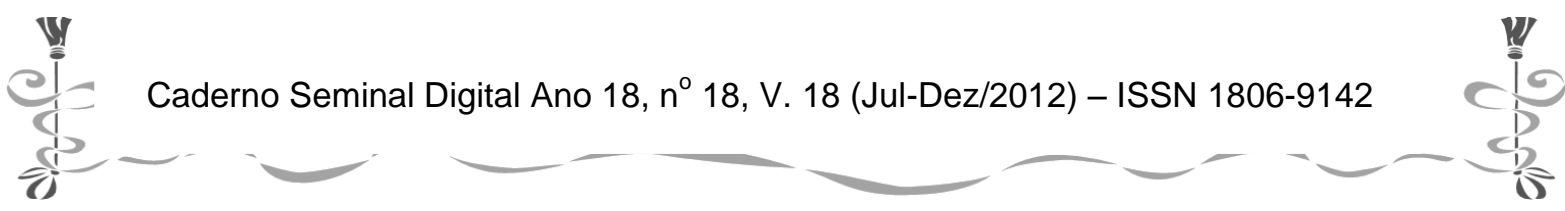




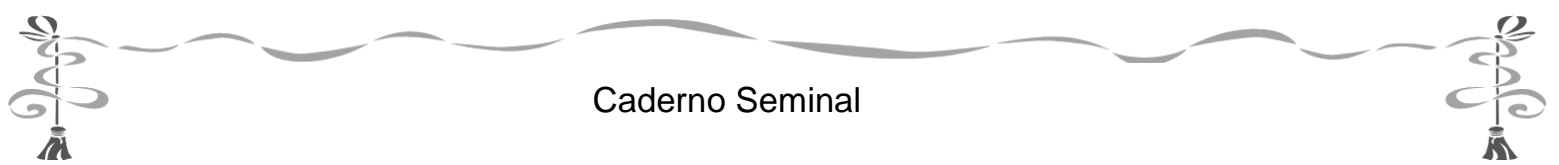

considera os gêneros discursivos/textuais como instrumentos de interação, mediadores de ações sociais, construídos por sujeitos ativos e participantes das diferentes esferas sociais. A fundamentação ancora-se também na concepção teórico-filosófica que fundamenta o CBEPM (AMOP, 2007), documento que organiza o ensino na região em que esse projeto é desenvolvido.

Há, assim, recorrência constante à interação verbal como condição para o trabalho com a linguagem. Essa compreensão, pautada numa abordagem dialética de produção do conhecimento, reconhece a linguagem como social, resultado de uma construção coletiva e de processos de interação. Tal fundamento sustenta-se em Bakhtin (2000, 2004) que propõe um olhar dialógico sobre a linguagem, considerando-a como um ato social que se realiza e se modifica nas relações sociais e, ao mesmo tempo, é meio para a interação humana e resultado dessa interação, já que seus sentidos não podem ser desvinculados do contexto de produção. A linguagem é, portanto, de natureza sócio-ideológica e tudo “[...] que é ideológico possui um significado e remete a algo situado fora de si mesmo" (BAKHTIN, 2004, p. 31 - grifo do autor).

Essa vertente teórica que também fundamenta o CBEPM (AMOP, 2007) considera a língua a partir de seu caráter discursivo, pois não a vê separada dos seus falantes e dos seus atos, tampouco das esferas sociais e dos valores ideológicos.

[...] pensar o ensino de Língua Portuguesa implica pensar na realidade da linguagem como algo que permeia todo o nosso cotidiano, articulando nossas relações com o mundo e com o outro, e com os modos como entendemos e produzimos essas relações. A percepção da natureza histórica e social da linguagem, estabelecida nos meios de produção, conduz-nos a compreender seu caráter dialógico, no sentido de que tudo o que dizemos, fazemo-lo dirigido a alguém, a um interlocutor concreto, quer dizer, sócio-historicamente situado. (AMOP, 2007, p. 144)

Enfatizando a necessidade de um trabalho com leitura, oralidade e escrita voltado aos usos sociais da língua, o CBEPM (AMOP, 2007) orienta que esse trabalho pode ser estruturado a partir do reconhecimento dos gêneros textuais ${ }^{60}$, apontando-os como objeto de ensino. "Os encaminhamentos metodológicos na concepção sociointeracionista da linguagem implicam a compreensão de que os gêneros são produzidos em função do uso geral da necessidade social” (AMOP, 2007, p. 147).

$\mathrm{Na}$ tentativa de apresentar um encaminhamento prático ao trabalho com os gêneros discursivos/textuais, o CBEPM (AMOP, 2007) recorre à perspectiva adotada por pesquisadores da Escola de Genebra, cujos representantes mais expressivos são Bernard Schneuwly, Joaquim Dolz e Jean-Paul Bronckart. Conceituando os gêneros

\footnotetext{
${ }^{60}$ O CBEPM (AMOP, 2007) adota a denominação "gêneros textuais", considerando a familiaridade dos interlocutores desse documento com o referido termo.
}

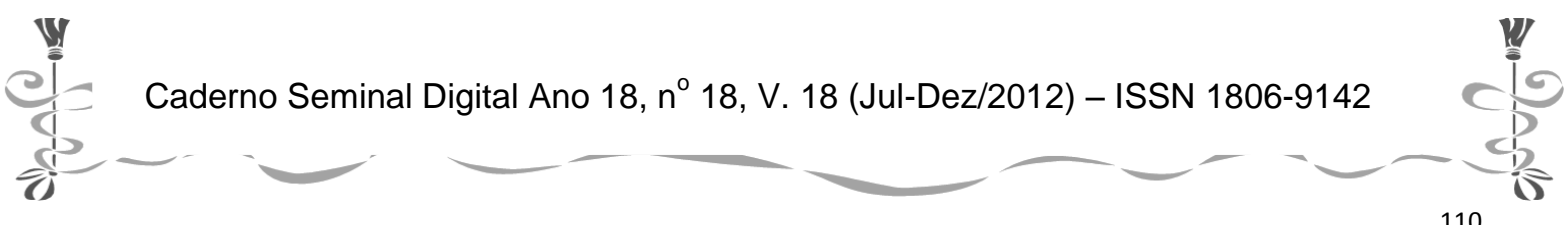




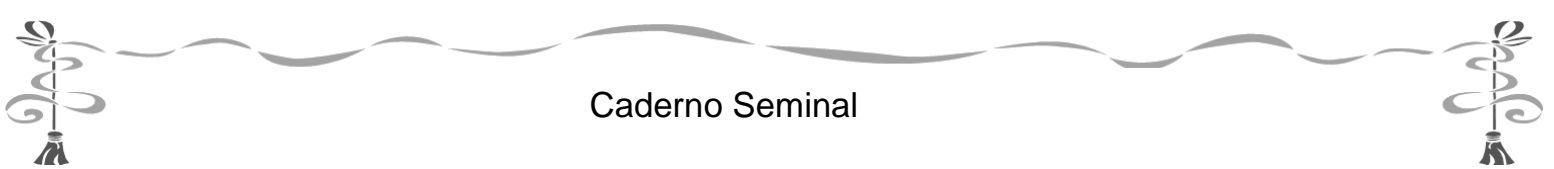

textuais como textos relativamente estáveis, elaborados a partir de determinados objetivos, Bronckart (2003) informa que:

$\mathrm{Na}$ escala sócio-histórica, os textos são produtos da atividade de linguagem em funcionamento permanente nas formações sociais: em função de seus objetivos, interesses e questões específicas, essas formações elaboram diferentes espécies de textos, que apresentam características relativamente estáveis (justificando-se que sejam chamadas de gêneros de textos) e que ficam disponíveis no intertexto como modelos indexados, para os contemporâneos e para as gerações posteriores. (BRONCKART, 2003, p. 137)

Como proposta para atender ao trabalho com os gêneros, os autores de Genebra apresentam um encaminhamento didático-metodológico conhecido como Sequência Didática (SD), o qual é assim apresentado pelo CBEPM:

O encaminhamento didático-metodológico que dá conta desse trabalho com os gêneros textuais é o da Sequência Didática (SD), proposta por Dolz, Noverraz e Schneuwly (2004). Trata-se de pensar e de planejar os conteúdos, de maneira sistemática, por meio da elaboração de um conjunto de atividades organizadas em torno de um gênero (oral ou escrito). (AMOP, 2007, p. 149)

Pautado nesse referencial teórico proposto pelo CBEPM (AMOP, 2007), recorrendo aos tópicos e descritores apresentados na Prova Brasil e articulando um processo de formação continuada comprometido com os objetivos do Programa Observatório da Educação, o projeto que desenvolvemos no oeste paranaense prevê, ao longo de seus quatro anos de atividades (2011/2014), a execução de diversas ações práticas, as quais já foram colocadas em prática ao longo do ano de 2011 e continuam em processo de realização no presente ano. A ação mais expressiva é a oferta de um processo de formação docente contínuo, sistematizado e organizado em diferentes áreas do conhecimento. No tocante à Língua Portuguesa, foram planejadas 80 horas de formação para os professores dos anos iniciais do Ensino Fundamental, em cada município inserido no projeto. O objetivo desse contato contínuo com os docentes está pautado no aprimoramento de suas práticas pedagógicas voltadas ao letramento, a fim de que as capacidades e habilidades de leitura, oralidade, escrita e análise linguística sejam trabalhadas de forma efetiva na sala de aula.

\section{Teoria e prática para o ensino da Língua Portuguesa: a formação continuada de docentes dos anos iniciais do Ensino Fundamental}

Tomando a concepção de linguagem como forma de interação e considerando a leitura com foco na interação autor-texto-leitor (KOCH; ELIAS, 2010), iniciamos os trabalhos previstos no projeto "Formação continuada para professores da educação básica nos anos iniciais: ações voltadas para a alfabetização em municípios com baixo IDEB na região

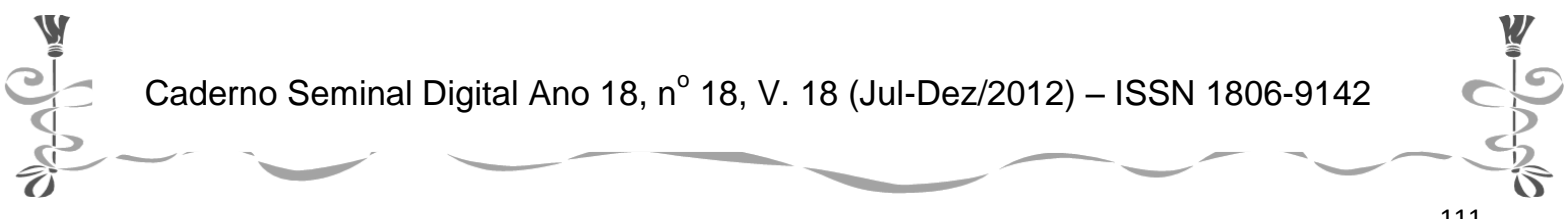




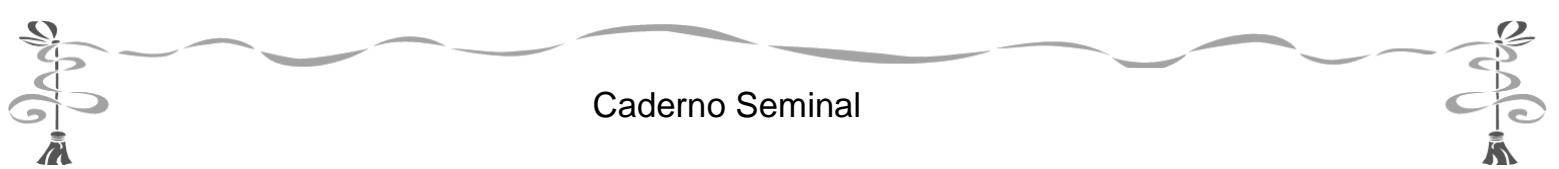

oeste do Paraná". Após a apresentação desse projeto aos municípios participantes, deu-se início a uma investigação sobre as políticas educacionais vigentes em cada município. Para isso, aplicamos questionários às equipes pedagógicas atuantes nas Secretarias Municipais de Educação e aos professores do Ensino Fundamental anos iniciais, na perspectiva de conhecer melhor esses sujeitos quanto à sua formação, tempo de serviço na área da educação, turma(s) em que atuam, dificuldades em relação às áreas de ensino, áreas afins à sua formação, hábitos de leitura etc.

Após, com o intuito de levantar as maiores dificuldades em leitura apresentadas pelos alunos para, posteriormente planejar as ações de formação continuada que seriam ofertadas em cada município, a equipe de bolsistas integrantes do projeto elaborou uma avaliação em Língua Portuguesa, pautada nos descritores da Prova Brasil, direcionando-a aos alunos do Ensino Fundamental - anos iniciais, das turmas de $3^{\circ}, 4^{\circ}$ e $5^{\circ}$ ano, e $3^{a}$ e $4^{a}$ série (nos municípios que ainda trabalhavam com o sistema de séries - Ensino Fundamental de 8 anos). Tal avaliação caracterizou-se como um simulado, pois atendeu ao formato das provas aplicadas pelo exame da Prova Brasil. Entretanto, além de respostas às questões objetivas, os alunos também elaboraram, ao final do simulado, um texto escrito, atendendo a uma situação de produção de acordo com um dos gêneros que apareceram ao longo da própria avaliação.

Os dados coletados na aplicação dos questionários e na aplicação dessa atividade avaliativa foram tabulados e organizados, com o objetivo de serem utilizados em pesquisas futuras e, especialmente, para indicarem o percurso necessário ao processo de formação continuada, estendido a cada município. Ou seja, orientaram as ações de formação que foram organizadas a partir dos problemas detectados nas respostas dos docentes e na realização da avaliação com os discentes.

A título de exemplificação da forma como se realizou esse trabalho de formação que ainda está em andamento, optamos por relatar, no presente texto, o trabalho desenvolvido em um dos municípios envolvidos no projeto. A intenção é mostrar como organizamos o trabalho com os pressupostos teórico-metodológicos presentes na proposta curricular, no caso o CBEPM (AMOP, 2007), e indicar a forma como abordamos as questões relacionadas à Prova Brasil, mostrando como a matriz de referência que conduz essa avaliação externa faz parte do dia a dia dos conteúdos indicados para o trabalho com a Língua Portuguesa nos anos iniciais do Ensino Fundamental. Dessa maneira, as formações aconteceram em forma de oficinas, envolvendo sempre estudo teórico e reflexões práticas sobre a teoria estudada, projetando tais reflexões para a produção de atividades direcionadas aos alunos de $1^{\circ}$ ao $5^{\circ}$ anos.

No município pesquisado, os trabalhos iniciais de formação continuada tiveram como objetivo um resgate sobre as concepções de linguagem que já fundamentaram e a(s) que ainda se manifestam no trabalho com a Língua Portuguesa na sala de aula.

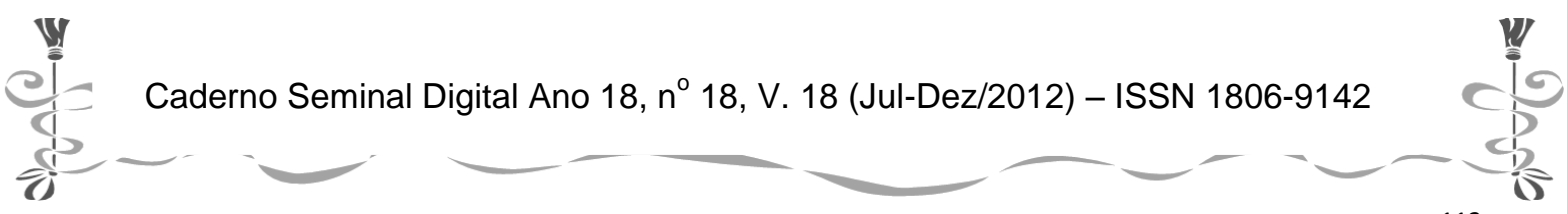




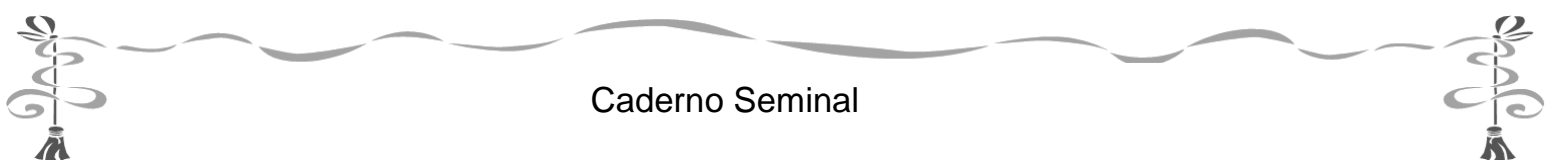

Os professores participantes dos momentos de formação ${ }^{61}$ foram convidados a fazerem uma leitura sistemática do referencial teórico de Língua Portuguesa presente no CBEPM (AMOP, 2007), a fim de perceberem os objetivos, encaminhamentos e ações práticas que subsidiam cada concepção de linguagem, conforme apresentado nesse documento.

$\mathrm{Na}$ sequência das ações, as atividades do processo de formação continuada voltaram-se para um estudo sistematizado da concepção de linguagem como forma de interação, a qual, entre outros aspectos, prevê o papel do interlocutor na produção de enunciados. Os professores conseguiram perceber que nessa concepção,

A compreensão de que ler e escrever significa mergulhar num universo conceitual que possibilita ao homem realizar processos mentais mais elaborados, pelo grau de abstração contido na linguagem escrita, exige a compreensão da totalidade da realidade percebida, e dos conhecimentos historicamente produzidos. (AMOP, 2007, p. 139)

Assim sendo, houve uma intensificação nos estudos relacionados à interação por meio da linguagem, fortalecendo os postulados de Bakhtin que defende uma linguagem na qual "o sentido da palavra é totalmente determinado por seu contexto e [...] há tantas significações possíveis quanto contextos possíveis" (BAKHTIN, 2004, p. 106).

Com relação à leitura, os encaminhamentos pautaram-se no foco da interação autortexto-leitor, considerando o caráter dialógico da língua (BAKHTIN, 2004). Os docentes realizaram atividades visualizando a importância da presença do interlocutor no processo de produção e organização de textos que circulam socialmente, percebendo, novamente, a linguagem como forma de interação. Dessa forma, reiteramos, junto aos professores, que o trabalho com a escrita e a leitura deve considerar que o discurso se consolida por meio de enunciados concretos e situados num determinado campo de atividade humana, pois

[...] cada esfera produz seus próprios gêneros. Todos os diversos campos da atividade humana estão ligados ao uso da linguagem. Compreende-se perfeitamente que o caráter e as formas desse uso sejam tão multiformes quanto os campos da atividade humana, o que, é claro, não contradiz a unidade nacional de uma língua. $\mathrm{O}$ emprego da língua efetua-se em forma de enunciados (orais e escritos) concretos e únicos, proferidos pelos integrantes desse ou daquele campo da atividade humana. (BAKHTIN, 2000, p. 261, grifo nosso).

${ }^{61}$ Num total aproximado de 40 professores dos anos iniciais do Ensino Fundamental.

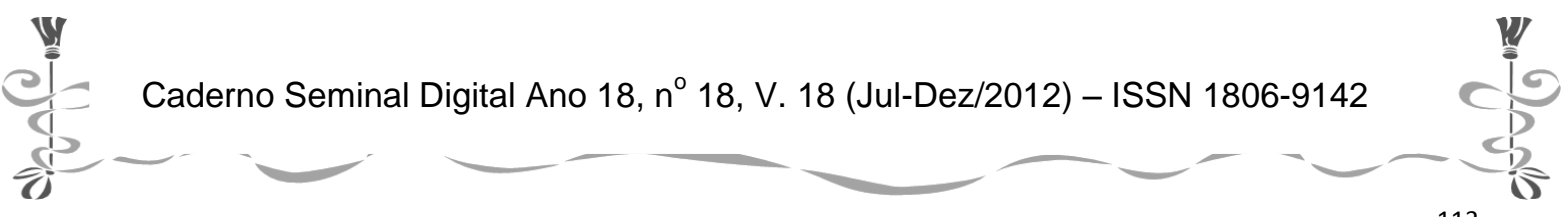




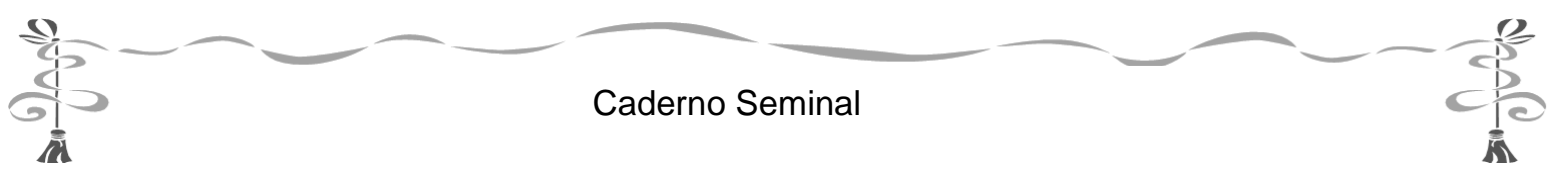

Partindo desse referencial, os docentes passaram a interagir com a teoria que fundamenta $\mathrm{o}$ trabalho com os gêneros discursivos nas atividades de Língua Portuguesa. Para isso, entretanto, houve uma retomada conceitual relacionada aos gêneros, informando sobre os estudos desenvolvidos por Bakhtin $(2000,2004)$ e pelos pesquisadores do grupo de Genebra, momento em que discutimos o encaminhamento didático-metodológico elaborado por esses pesquisadores: a proposta da Sequência Didática (SD) (DOLZ; NOVERRAZ; SCHNEUWLY, 2004), destacada inclusive no CBEPM (AMOP, 2007), no qual se adota a adaptação conforme Costa-Hübes (2008). Ainda que se apresente como um encaminhamento presente no referencial curricular que orienta o ensino nessa região, os docentes do município focalizado (tal como aconteceu também em outros municípios participantes do projeto), tinham muitas dúvidas para organizar o trabalho conforme indicado nessa proposta.

Uma sequência didática tem, precisamente, a finalidade de ajudar o aluno a dominar melhor um gênero de texto, permitindo-lhe, assim, escrever ou falar de uma maneira mais adequada numa dada situação de comunicação (DOLZ; NOVERRAZ; SCHNEUWLY, 2004, p. 97).

Partindo da teoria que informa sobre a prática, os professores passaram a perceber que, organizada a partir de uma ordem de atividades, essa orientação metodológica, que no Currículo foi adaptada por Costa-Hübes (apud AMOP, 2007), propõe um olhar para o texto, considerando-o como a materialização de um gênero discursivo que apresenta função social, contexto de produção, organização composicional e marcas linguísticas que definem seu estilo.

Ao falar sobre esses aspectos que caracterizam um gênero discursivo, inserimos, nas discussões, os resultados da avaliação realizada com os alunos, mostrando aos docentes que os questionamentos presentes na Prova Brasil fazem parte de uma matriz de referência que contempla muitas das questões que são trabalhadas constantemente no ensino da Língua Portuguesa. No momento que abordamos esses descritores, evidenciamos atividades que envolvem a materialidade de um gênero discursivo, enfocando os elementos que o constituem de uma forma geral. Desse modo, os docentes tiveram contato com questões relacionadas a: procedimentos de leitura, implicações do suporte, do gênero e/ou enunciador na compreensão do texto, relação entre textos, coerência e coesão no processamento do texto; relações entre recursos expressivos e efeitos de sentido; variação linguística, uma vez que são os tópicos que compõem a matriz de referência da Prova Brasil.

A principal estratégia utilizada, relacionada aos descritores da Prova Brasil, baseouse, inicialmente, na compreensão de cada descritor, seguida de elaboração, por parte dos docentes, de atividades relacionadas a cada descritor. Com isso, houve um entendimento de que o trabalho com os tópicos e descritores da Prova Brasil

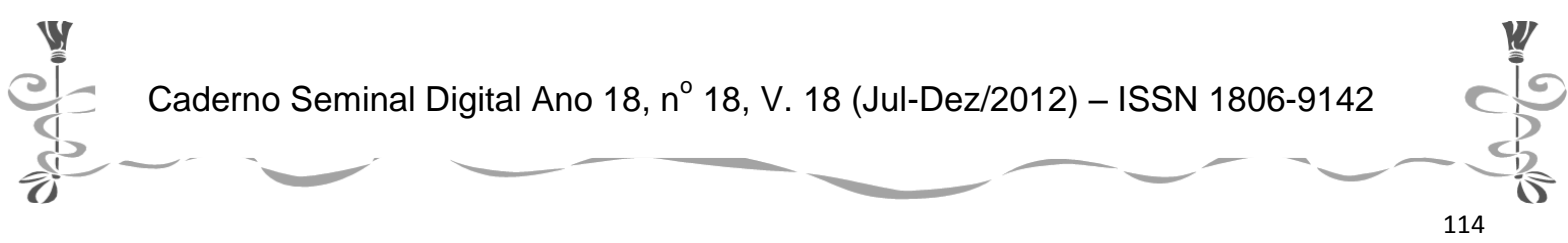




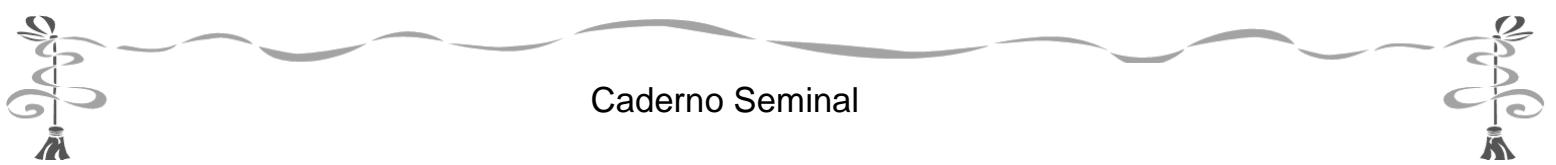

perpassa todo um encaminhamento comprometido com a leitura e com compreensão do texto, exigindo que este seja encarado como um enunciado concreto, situado num determinado campo de atividade humana (BAKHTIN, 2000), produzido com um propósito de interação entre locutor e interlocutor (es).

Com a elaboração de atividades, os professores compreenderam os objetivos da matriz de referência da Prova Brasil, bem como dos tópicos e descritores que a compõem. Também tiveram um contato maior com a teoria que fundamenta suas práticas cotidianas no ensino da Língua Portuguesa, além de interagirem com diferentes atividades que possibilitam um trabalho voltado à linguagem como forma de interação.

\section{Considerações finais}

Essa breve apresentação teve como objetivo ressaltar alguns encaminhamentos realizados pelo projeto "Formação continuada para professores da educação básica nos anos iniciais: ações voltadas para a alfabetização em municípios com baixo IDEB na região oeste do Paraná" acerca do trabalho com a escrita e a leitura na formação continuada de docentes, guiado por um referencial curricular que norteia o trabalho com a Língua Portuguesa e pela matriz de referência da Prova Brasil.

A partir de dados revelados em pesquisa realizada junto aos docentes e por meio de uma avaliação aplicada aos alunos, encaminhamos conteúdos que pudessem atender, primeiramente, aos docentes, para em seguida, estenderem-se aos discentes. Houve um grande empenho por parte dos professores participantes da formação continuada para interagirem com conteúdos, até então, desconhecidos por muitos.

Ainda que os trabalhos de formação continuada desenvolvidos no projeto estejam em andamento, é possível verificar que a prática da escrita e da leitura na sala de aula necessita de consistentes subsídios teóricos e metodológicos que possam amparar os docentes na elaboração de seus planos de ensino. O intuito de diagnosticar os problemas relacionados a esses aspectos do ensino da Língua Portuguesa, para, posteriormente, abordá-los no processo de formação continuada, foi condizente com os anseios que os docentes depositam nesse processo.

Finalmente, ressaltamos que o fundamento que ampara as ações de formação baseia-se no pressuposto de que a formação continuada é uma "[...] possibilidade de trabalho com os conteúdos historicamente acumulados e a busca da autonomia intelectual e moral através, justamente, da transmissão das formas mais elevadas e desenvolvidas do conhecimento socialmente existente" (DUARTE, 2001, p. 36). Por isso, almejamos que esses momentos de formação possam mediar um (re) direcionamento da prática docente, propondo a inserção dos alunos no âmbito da escrita e da leitura numa concepção dialógica de linguagem.

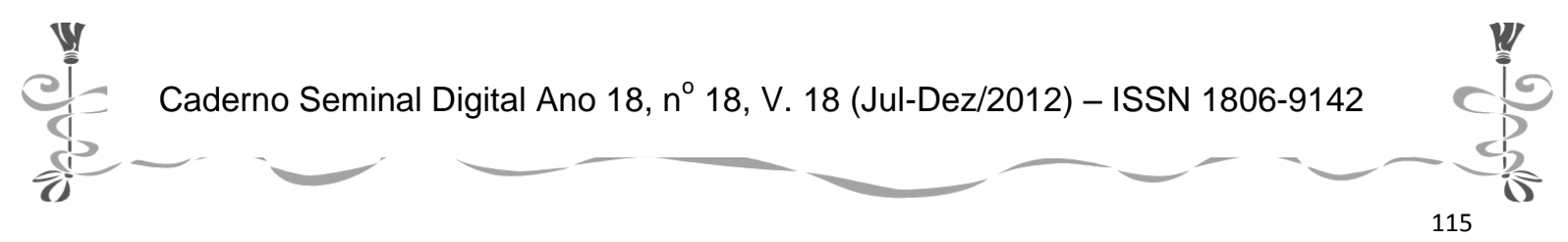




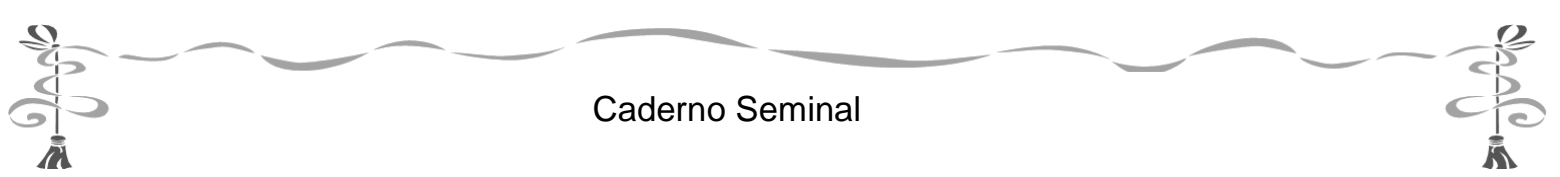

\section{Referências}

AMOP - Associação dos Municípios do Oeste do Paraná. Currículo Básico para a Escola Pública Municipal: Educação Infantil e Ensino Fundamental (anos iniciais). Cascavel: ASSOESTE, 2007.

BAKHTIN, Mikhail. Estética da Criação Verbal. 3. ed. São Paulo: Martins Fontes, 2000. Marxismo e Filosofia da Linguagem. 11. ed. São Paulo: Hucitec, 2004.

BRONCKART, Jean-Paul. Atividades de linguagem, textos e discursos. São Paulo: Educ, 2003.

COSTA-HÜBES, Terezinha da Conceição. O processo de formação continuada dos professores no Oeste do Paraná: um resgate histórico-reflexivo da formação em Língua Portuguesa. Londrina, UEL, 2008 (Tese de Doutorado).

DOLZ, Joaquim; NOVERRAZ, Michele; SCHNEUWLY, Bernard. Sequências didáticas para o oral e a escrita: apresentação de um procedimento. In: DOLZ, Joaquim; SCHNEUWLY, Bernard. Gêneros orais e escritos na escola. Tradução e organização: Roxane Rojo e Glaís Sales Cordeiro. Campinas, SP: Mercado de Letras, 2004. p. 95-128.

DUARTE, Newton. Vygotsky e o "aprender a aprender": crítica às apropriações neoliberais e pós-modernas da teoria vigotskyana. Campinas, SP. Autores Associados, 2001.

KOCH, Ingedore Grünfeld Villaça; ELIAS, Vanda Maria. Ler e compreender: os sentidos do texto. 3. ed. São Paulo: Contexto, 2010.

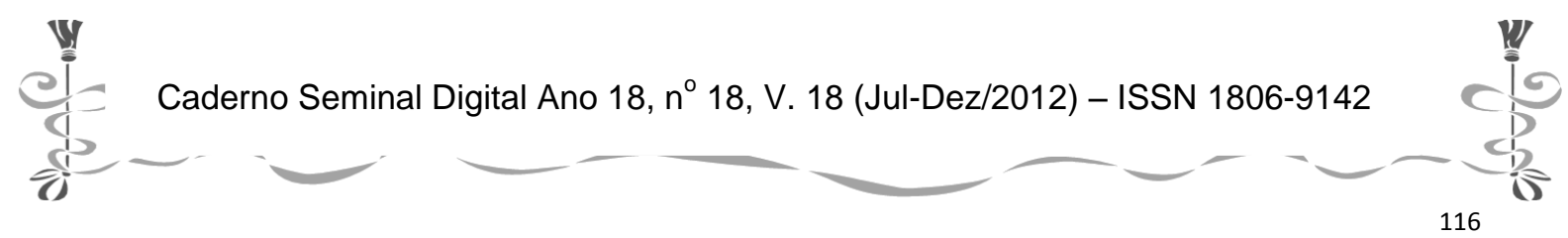

